\title{
Analysis of SARS-CoV-2 RNA on Surfaces in New York City
}

Rabia Karani ${ }^{1}$, Qun Zeng ${ }^{1}$, Aliaa Abdelhakim ${ }^{1}$, Vlad Diaconita ${ }^{1}$, Omar Moussa ${ }^{1}$, Henry W Zhou' ${ }^{2}$, Tarun Sharma ${ }^{1}$, Marium Sohail ${ }^{2}$, Zachary Snow $^{2}$, Alexis Kassotis², Angela Y Chang' ${ }^{2}$, Saurabh Sudesh ${ }^{2}$, Stanley Chang ${ }^{1}$, Jason D Horowitz', Lisa Park', Danielle Trief ${ }^{1}$, Tongalp H Tezel ${ }^{1}$

${ }^{1}$ Department of Ophthalmology, Edward S. Harkness Eye Institute, Columbia University Irving Medical Center, New York Presbyterian Hospital, New York City, New York, USA

${ }^{2}$ Columbia University, Vagelos College of Physicians \& Surgeons, New York City, New York, USA

\section{Correspondence to:}

Tongalp H. Tezel, M.D.

Chang Family Professor of Ophthalmology

Edward S. Harkness Eye Institute

Columbia University Irving Medical Center,

New York Presbyterian Hospital

635 W. 165th St.

New York, New York

USA, 10032

tht2115@cumc.columbia.edu
Background This study sought to determine the presence of SARS-CoV-2 virus on surfaces that trainees and faculty of an academic eye clinic came into contact with during daily life at the time of the COVID-19 pandemic in New York City.

Methods This cross-sectional analysis involved collection of at least two samples by teams on four different days (November 9, 2020 - December 18, 2020) using sterile swabs (Puritan HydraFlock, Garden Grove, CA). Collection sites were grouped into four zones depending on proximity and amount of time personnel spent there. Samples were transported to the laboratory in transport medium and RNA was extracted using the QIAamp DSP Viral RNA Mini Kit (Qiagen, Germantown, MD). Presence of viral RNA was investigated using the Luna Universal Probe One-step RT-qPCR kit (New England Biolabs, Ipwsich, MA).

Results 834 samples were submitted. Two were positive for SARS-CoV-2 RNA. The first was a sample from a patient bathroom sink handle in the main emergency department. The second was a nasal swab sample from a staff member who had been assigned to collect samples. Prior to this positive result, this asymptomatic staff member had tested positive for COVID-19, had quarantined for two weeks, and had received a negative test.

Conclusion Though COVID-19 is currently widespread in the United States, this study shows that health care personnel working in New York City at the Columbia University Irving Medical Center have a low chance of encountering viral RNA on surfaces they are in close contact with during daily life.

In December 2019, an outbreak of pneumonia caused by a novel coronavirus called severe acute respiratory syndrome coronavirus 2 (SARS-CoV-2) was reported in Wuhan, China [1-3]. Infections spread across China and other countries over the following weeks $[4,5]$. In January of 2020, the World Health Organization (WHO) announced that the outbreak was a Public Health Emergency of International Concern (PHEIC) [6]. The disease caused by the novel coronavirus was named Coronavirus Disease 2019 (COVID-19) by the WHO and declared a global pandemic in February and March of $2020[7,8]$. In the United States, the first COVID-19 patient was reported on January 15, 2020, in Washington state. Coronavirus quickly spread throughout the United States, turning it into the global epicenter of the disease with the greatest number of cases and deaths. The first case of COVID-19 in New York was reported on February 29, 2020 and as of April 2020, New York was one of the worst hit states in the United States, with 195749 cases making it the epicenter within the country [9]. 
Transmission of SARS-CoV-2 occurs primarily via respiratory droplets from face-to-face contact during talking, coughing, and sneezing. Epidemiologic data suggest that prolonged exposure to an asymptomatic infected person and brief exposures to persons who are symptomatic are associated with higher risk for transmission [10]. Aerosol spread may occur, but the role of spread in humans is unclear [11,12]. Another possible mode of transmission is contact surface spread. Studies have suggested that the virus is able to survive on the surfaces of various materials, such as plastic, metal, or glass, from two hours to nine days [13]. Given the ability of the virus to remain viable on dry surfaces for sufficient time, forward transmission has been suggested by a few studies [14-16]. Viral RNA particles were detected on the surfaces of cabins up to 17 days after patient disembarkation in a study of cruise ship outbreaks [17]. Aytogan et al. demonstrated the presence of COVID-19 viral particles using real-time polymerase chain reaction (RT-PCR) on surfaces in an eye examination room despite a triage system to exclude patients with coronavirus disease [18]. In addition, previous studies on the 2003 outbreak of severe acute respiratory syndrome (SARS) have identified viral particles on surfaces of two hospitals in Thailand and Taiwan [19].

WHO recommendations are to ensure that environmental surfaces are consistently and correctly disinfected in order to reduce viral load and the risk of transmission through contaminated surfaces. Environmental surfaces must be thoroughly cleaned with water and disinfectant. Using hospital disinfectants such as sodium hypochlorite can be an effective method [20]. Disinfectants with 62\%-71\% concentration of ethanol or bleach with a concentration of $0.1 \%$ sodium hypochlorite were proven to reduce coronavirus infectivity on surfaces within one minute of exposure [13]. Disinfection protocols were implemented on various surfaces around New York City, such as bus stops, subway stations, trains, and outdoor spaces. In addition, quarantine measures and travel restrictions have aided in the control of COVID-19 spread, where asymptomatic individuals who traveled out of state were required to quarantine for ten days at home except for essential workers. Multiple measures to limit the transmission of infection were implemented at Columbia University Irving Medical Center/Edward S. Harkness Eye Institute including proper personal protective equipment (PPE) for patients and staff, a pre-arrival COVID-19 screening, a pre-arrival check-in process and screening at a welcome station for COVID-19 symptoms, disinfection and cleaning throughout each day, and visitor limitations as per Centers for Disease Control and Prevention (CDC) recommendations. Despite all these precautions, risk of health care personnel's exposure to SARS-Co-V-2 during their daily life varied depending on the time they spent in the workplace. Although the efficacy of precautions for preventing SARS-CoV-2 contamination through environmental surfaces at hospitals clinics have been well described in the past, a comprehensive study of the risk of the physicians, staff, and trainees at an academic center to come across viral RNA in their daily life along the work-home-leisure axis has not been studied. This cross-sectional study was designed to detect the presence of COVID-19 mRNA on various surfaces that workers of an academic medical center may encounter during their daily life at the time of the COVID-19 pandemic in New York City.

\section{METHODS}

This cross-sectional analysis did not require approval by the Columbia University Irving Medical Center institutional review board because this is a non-interventional study involving surfaces and routine SARS-CoV-2 PCR tests of volunteer sample collectors. Patients or the public were not involved in the design, or conduct, or reporting, or dissemination plans of our research. Samples were collected by faculty and trainees of the Harkness Eye Institute at the Columbia University Irving Medical Center. Each member of the collection team was assigned to a specific location that was encountered by the team member in their daily life.

\section{Sample collection}

Samples were collected by swabbing a wide surface area of a particular location using a sterile swab (Puritan HydraFlock, Garden Grove, CA). This swab was then placed into a MicroTest Tube with Transport medium (ThermoFisher Scientific R12587), refrigerated, and processed within 48 hours. Care was taken to prevent cross-contamination. Swabs were opened separately, the surface was sampled, and the swab was placed in a vial prior to proceeding to the next surface. Members of the swabbing team were tested for COVID-19 prior to starting with the collection.

Sample collection occurred in two phases. The first phase took place over two weeks from November 9-19, 2020. The second phase took place again over two weeks from December 7-18, 2020. During the second phase of sampling, sample collectors revisited the same places they had collected from in the initial phase of the study. During each phase, each location was visited twice within the same week to obtain a sample. 


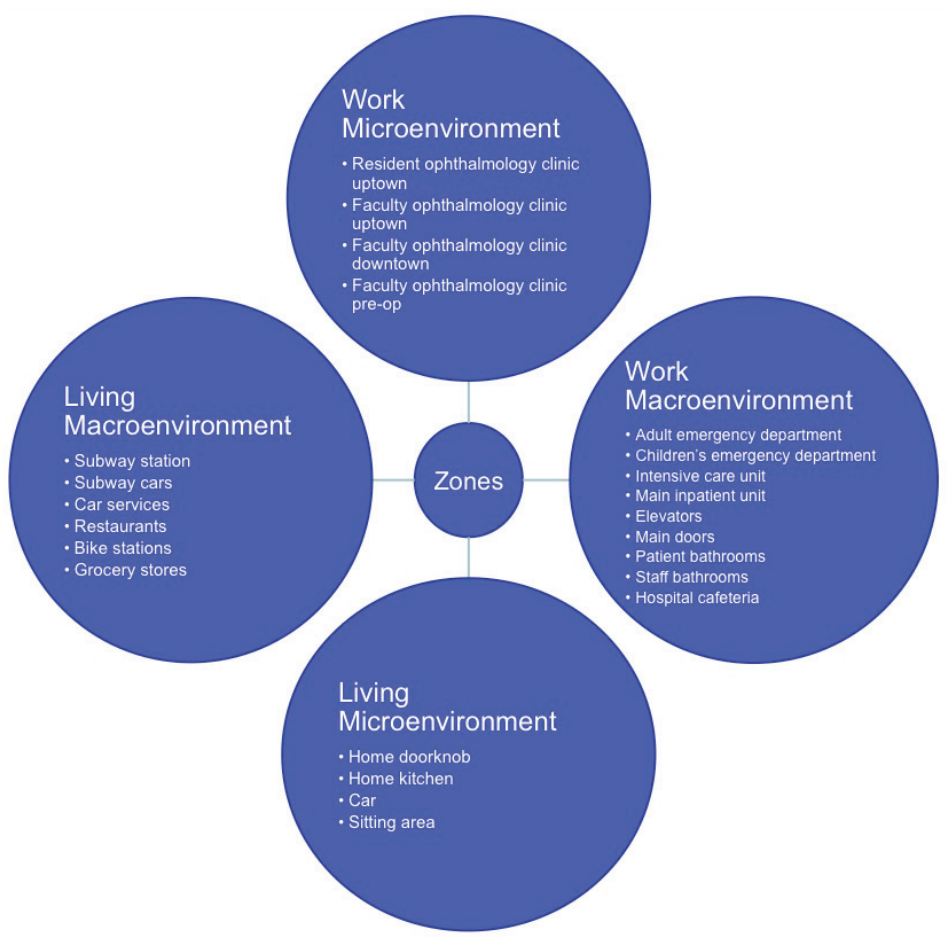

Samples were collected from several different locations grouped into 4 zones (Figure 1). Zones included: (1) Work microenvironment: resident ophthalmology clinic in uptown Manhattan, faculty ophthalmology clinic in uptown Manhattan, faculty ophthalmology clinic in downtown Manhattan, ophthalmology pre-operative area. Samples in all clinics were collected before and after cleaning, and before cleaning in the pre-operative area. (2) Work macroenvironment: intensive care unit, children's hospital emergency department, adult emergency department, main inpatient unit, elevators, main doors, patient bathrooms, staff bathrooms, hospital cafeteria. Samples were taken before cleaning in the inpatient units, and at random in other areas of the hospital. (3) Living microenvironment: home doorknob, home kitchen, car, sitting area. Samples were taken at random. (4) Living macroenvironment: subway station, subway cars, car services, restaurants, Citi Bike stations, grocery stores. Samples were taken at random. Surfaces swabbed in each zone included the following (Figure 2).

Figure 1. Zones for sample collection.
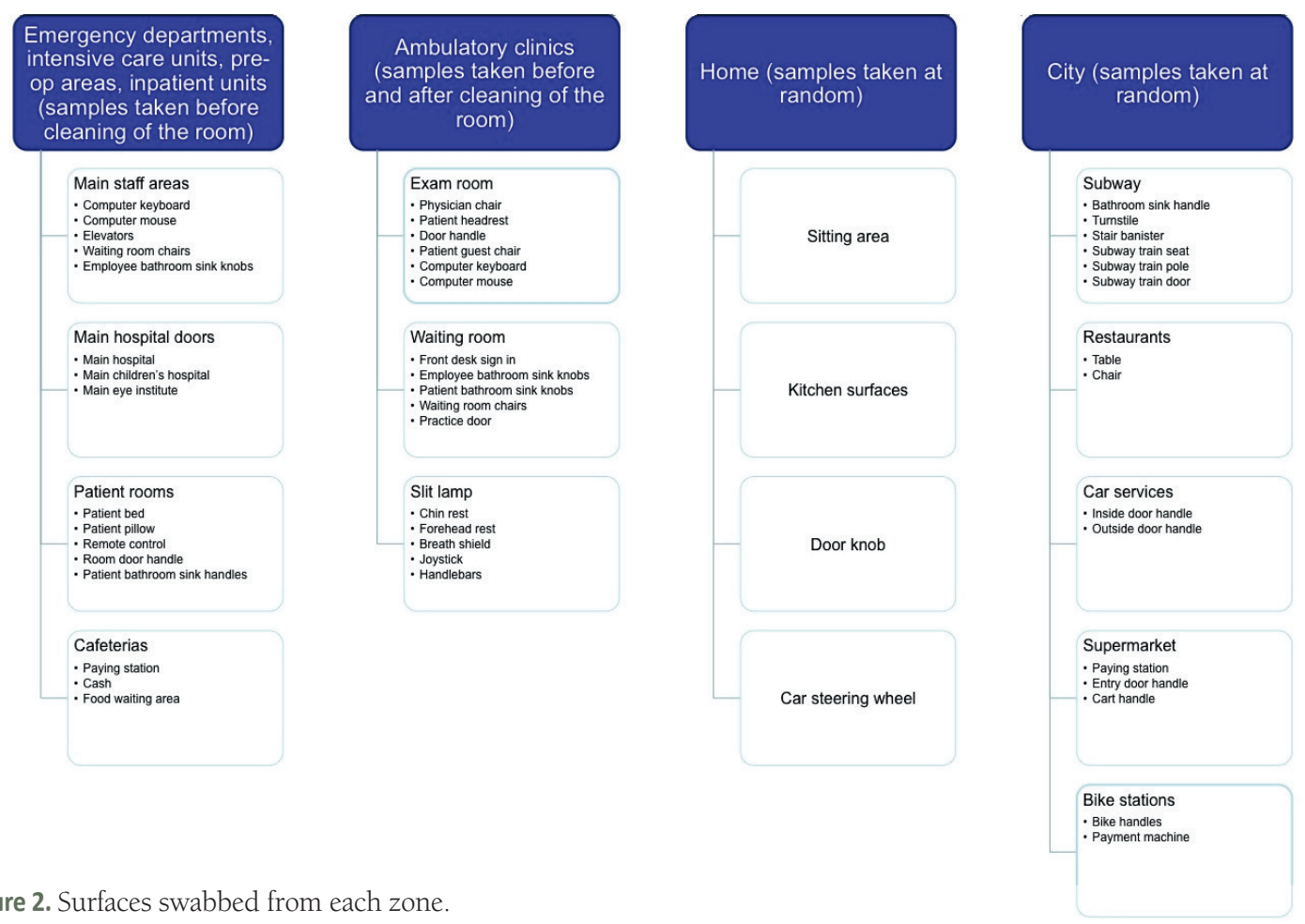

Figure 2. Surfaces swabbed from each zone.

Zone 1 or clinic rooms in the work microenvironment were thoroughly disinfected with anti-viricidal wipes after every patient visit. Zone 2 or rooms in the work macroenvironment were also cleaned after each patient visit. Shared spaces such as elevators, doors, and bathrooms were cleaned daily. Zone 3 or living macroenvironment spaces were cleaned per the resident's discretion. Zone 4 or living macroenvironment spaces were cleaned daily as well. The Metropolitan Transport Authority in New York City implemented a daily disinfection routine for subway cars and stations using antimicrobial technology and UV light technology [21]. Per CDC and New York State Department of Agriculture and Markets recommendations, many restaurants and grocery stores were cleaned daily with antimicrobials [22,23]. Citi Bike stations were also cleaned daily with antimicrobials, and car services were cleaned per the driver's discretion [24]. 


\section{Processing}

Sample processing occurred by extracting nucleic acid using a commercial viral RNA extraction kit (QIAamp DSP Viral RNA Mini Kit, Qiagen, Germantown, MD). The Luna Universal Probe One-step RT-qPCR kit (New England Biolabs, Ipwsich, MA) was then used with standardized primer and probe concentrations of $500 \mathrm{nM}$ of forward and reverse primer, and $250 \mathrm{nM}$ of probe, for the 2019-nCoV_N1, 2019-nCoV_N2, and RP (human control) primer-probe sets to detect SARS-CoV-2 in each sample. PCR cycler conditions were reverse transcription for 10 minutes at $55^{\circ} \mathrm{C}$, initial denaturation for 1 minute at $95^{\circ} \mathrm{C}$, followed by 45 cycles of 10 seconds at $95^{\circ} \mathrm{C}$ and 30 seconds at $55^{\circ} \mathrm{C}$ on CFX Connect Real Time System (Biorad).

Analysis of data was primarily descriptive.

\section{RESULTS}

Out of a total of 834 swabs, only two $(0.24 \%)$ samples were positive. The first was a sample from a patient bathroom sink handle in the main emergency department, and the second was a nasal swab from a staff member who

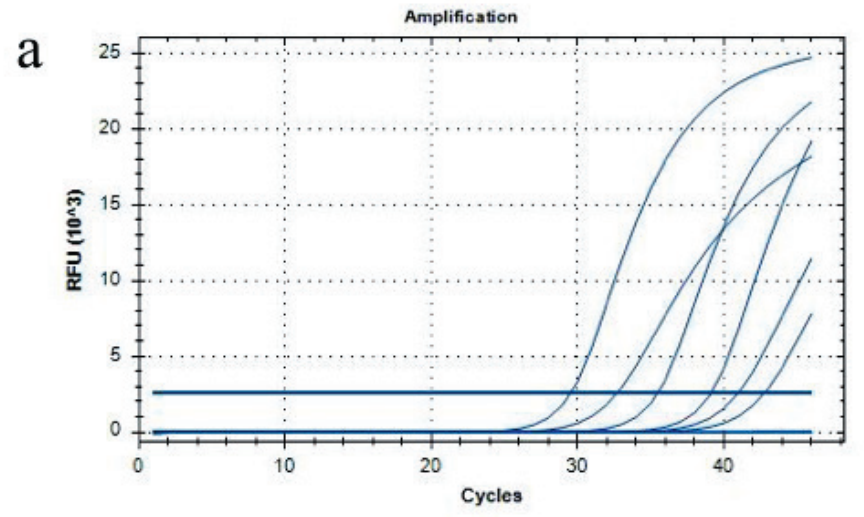
had been assigned to collect samples. The positive sample from the bathroom sink handle was collected on November 17, 2020 (Figure 3, Panel A). On this day, the effective reproduction number $\left(\mathrm{R}_{\mathrm{t}}\right)$ of the virus was 1.14 and the number of positive tests that day were 5088 in New York state [25]. In the emergency department of our sister hospital, New York Presbyterian Hospital Cornell, there were 864 visits related to COVID-19 in the 7-day period beginning with this day. Therefore, there were about 123 COVID-19 related ED visits on November 20, 2020 in the New York Presbyterian ED. COVID-19 related visits included patients who presented for suspected or confirmed COVID-19, or presented for testing [26]. The positive sample from the staff member was collected on December 14, 2020 (Figure 3,

b
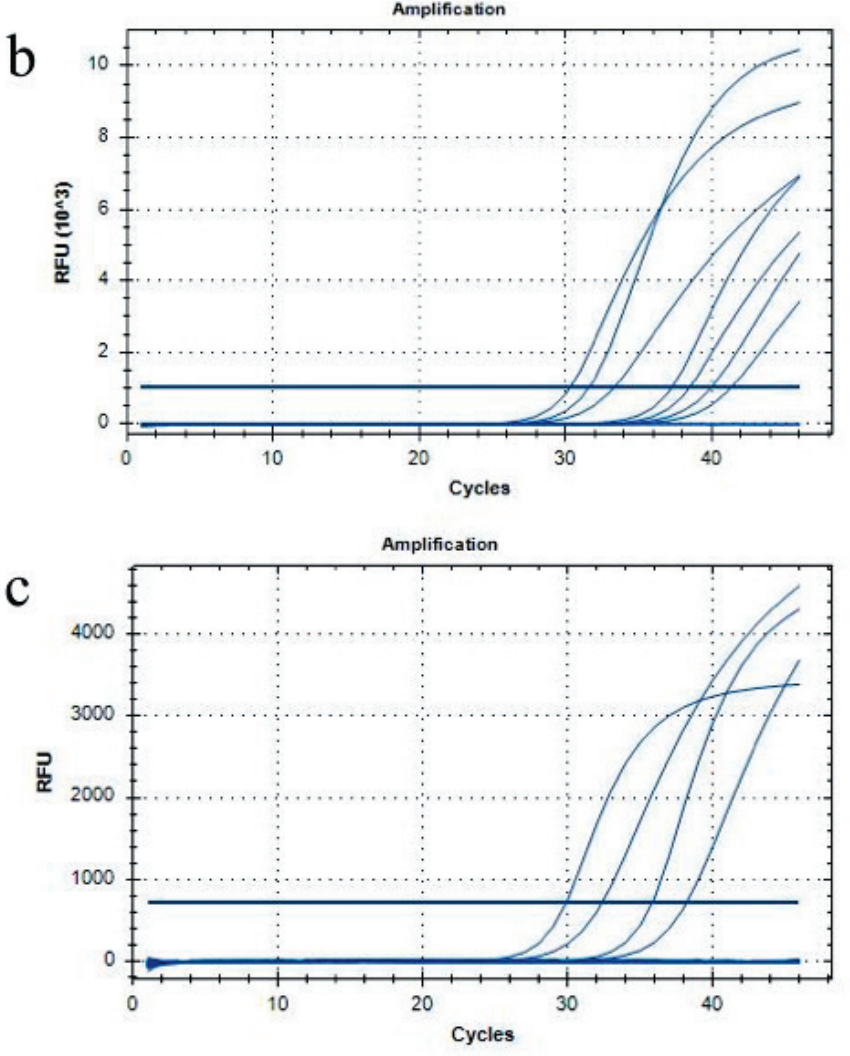

Figure 3. RT-PCR. RT-PCR cycles showing positivity for SARS-CoV2mRNA from a bathroom sink handle (Panel A) and from a nasal swab of a participant (Panel B). RT-PCR cycles showing no positive results (Panel C).
Panel B). On this day, the effective reproduction number $\left(R_{t}\right)$ of the virus was 1.10 and the number of positive tests that day were 9044 in New York state [25]. In the New York Presbyterian Hospital Emergency Department, there were 598 visits related to COVID-19 in the 7-day period centered around this day. Therefore, there were an estimated 85 COVID-19 related ED visits on December 14, 2020 in the New York Presbyterian ED [26]. Prior to this positive test result, this asymptomatic staff member had tested positive for COVID-19, quarantined for two weeks, and had received one negative test result.

The rest of the samples were negative for 2019-nCoV_N1 and 2019-nCoV_N2 primers (Figure 3, Panel C), although many were positive for the RP (human control) primer (Table 1).

\section{DISCUSSION}

Though COVID-19 is currently widespread around New York City, we found evidence that there was minimal risk of exposure to COVID-19 through contaminated surfaces encountered in the daily lives of faculty and trainees at an academic medical center in New York City. Considering the $1.77 \%-2.39 \%$ citywide test positivity among individuals during the time this study was conducted, the likelihood of faculty and trainees being exposed to SARS-CoV-2 virus from contaminated surfaces is 100 times less likely than acquiring COVID-19 from an infected individual. 
Table 1. Areas positive for human control primer

\begin{tabular}{ll}
\hline Areas positive for human control primer & \\
\hline All nasal swabs & Hospital computer mouse \\
\hline Slit lamp chin rest & Hospital computer keyboard \\
\hline Slit lamp forehead rest & Hospital employee bathroom sink knob \\
\hline Slit lamp breath shield & Hospital patient bathroom sink handle \\
\hline Slit lamp handlebars & Hospital patient room door handle \\
\hline Slit lamp joystick & Hospital main elevator lobby button \\
\hline Slit lamp applanation tip & Hospital floor waiting room chair \\
\hline Clinic exam room patient headrest & Home swab \\
\hline Clinic exam room door handle & Bike station bike handles \\
\hline Clinic exam room physician chair & Bike station payment machine \\
\hline Clinic exam room guest chair & Subway stair banister \\
\hline Clinic room computer keyboard & Subway bathroom sink handle \\
\hline Clinic employee bathroom sink knobs & Subway train seat \\
\hline Clinic patient bathroom sink knobs & Subway train pole \\
\hline Clinic front desk sign in & Subway door \\
\hline Clinic practice door & Subway turnstile \\
\hline Hospital patient bed & Subway elevator \\
\hline Hospital patient pillow & Car service door handle \\
\hline Hospital patient room remote control & Car service seat \\
\hline Hospital patient room door handle & Main hospital door \\
\hline Hospital cafeteria paying station & Supermarket cart handle \\
\hline Hospital cafeteria cash & Supermarket paying station \\
\hline Hospital cafeteria food waiting area & \\
\hline
\end{tabular}

In our study, we found evidence of COVID-19 on a bathroom sink handle in the main emergency department. Several studies of COVID-19 that acquired air and surface samples taken from the rooms of COVID positive patients showed higher levels of contamination in bathrooms. Our findings were consistent with these prior studies supporting the view that viral shedding continues for a longer term from the gastrointestinal route $[27,28]$. Our study also found COVID-19 mRNA in the nasal passage of a study member who had already tested positive for COVID-19, had quarantined for two weeks, and had already had one negative test. All samples collected by this study team member were negative. Studies have shown that COVID-19 positivity can occur several weeks after active infection or negative testing. This can be attributed to low viral load remaining after active infection, re-infection with a new strain of virus, false positivity on RT-PCR or simply shedding of the viral RNA but not the whole virus itself. In many cases, the viral load is enough to be detected by PCR testing, but not enough for inoculation of others $[29,30]$. This staff member was allowed to continue swabbing.

We hypothesize that surfaces were largely negative throughout the city, in the hospital, and in the clinic environment due to strict infection control policies. All subways, restaurants, supermarkets, and other services in the city enacted strict disinfection protocols and universal masking policies. Though the virus can have surface stability for up to 72 hours, studies have shown that the use of viricidal agents was effective in eliminating human coronaviruses such as SARS and MERS, and that masking can reduce the transmission of virus by up to $90 \%[13,14,31,32]$. In addition, the city implemented strict quarantine and social distancing policies, which were found to be important in reducing the incidence and mortality of COVID-19 [33].

In the hospital, all admitted patients were swabbed for COVID-19, and were isolated if they tested positive for the virus. Our study did not involve swabbing the rooms of COVID-19 positive patients since these areas were not the routine places the staff were visiting in their daily activities. In ambulatory care areas, patient COVID-19 status was unknown, but rooms were cleaned after each patient exam and strict screening protocols were implemented. Staff members in the hospital and in the ophthalmology clinic were known to be healthy and were screened daily, with frequent testing occurring in the case of exposure, travel, or upper respiratory or other symptoms. Visitors were also limited in the inpatient units, clinics, and emergency departments at this time, further limiting the possibility of transmission of COVID-19. One study showed that almost $4 \%$ of asymptomatic visitors to the hospital were positive for COVID-19, highlighting the importance of visitor restriction [34]. In addition, screening protocols, universal masking, strict PPE protocols, and frequent cleaning procedures were implemented throughout the different areas of the hospital and clinic per CDC guidelines [35]. A recent study at a large academic medical center demonstrated that with proper infection control protocols, the incidence of nosocomial COVID-19 in patients admitted for non-COVID reasons was 1 out of 8370 patients [36].

This study had several limitations. First, RT-PCR establishes only the presence of the viral RNA, but cannot discern the presence of the whole virus and thus, infectivity. Thus, the study cannot reach a conclusion about the 
risk of transmission from the positive sample that we found. Additionally, since our goal was to analyze the presence of the virus on surfaces along the work-home-leisure axis of the personnel, we excluded the rooms of COVID-19 positive patients. Obviously, physicians who consulted with these patients may have a higher risk of exposure to COVID-19. Also, the targeted viral gene and the primers that were used might have affected the ability of viral RNA detection. We used primers suggested by the CDC that were commonly used to test for the presence of SARS-CoV-2 for research purposes to minimize the impact of marker-induced sensitivity problems [37]. Finally, our samples taken from the city were gathered at random times. Although the infection rate remained stable in New York for a long time there may be variances among different times of the day which may affect the presence of SARS-CoV-2 RNA on environmental surfaces.

\section{CONCLUSION}

Our study shows that the virus is less likely to be transmitted by contact with surfaces in New York City. Our study also shows that decontamination, universal masking, visitor restriction, PPE protocols, quarantine protocols, and outdoor dining and recreation limit the spread of the virus. Finally, our study further bolsters the hypothesis that the virus has mainly respiratory transmissibility.

Disclaimer: The views expressed in the submitted article are the authors' own and not an official position of the institu-
tion or funder.
Ethics approval: This study did not require ethics approval as it did not involve human participants. Nasal swabs from
volunteer sample collectors were part of routine SARS-CoV-2 PCR testing.
Funding: The Department of Ophthalmology at Columbia University Irving Medical Center is supported by an unre-
stricted grant from Research to Prevent Blindness. Dr Tezel is supported by a grant from the Foley Research Fund. Funder
had no involvement in study design, collection, analysis, interpretation of data, writing of the report, and in the decision
to submit the paper for publication.
Authorship contributions: THT had full access to all the data in the study and takes responsibility for the integrity of
the data and the accuracy of the data analysis. Concept and design: AA, VD, RK, THT, QZ. Acquisition, analysis, or inter-
pretation of data: All authors. Drafting of the manuscript: RK, OM, THT. Critical revision of the manuscript for import-
ant intellectual content: All authors. Administrative, technical, or material support: All authors. Supervision: RK, THT.
Competing interests: Dr Chang reports personal fees from Genentech and travel reimbursement from Alcon, outside the
submitted work. Dr Horowitz reports personal fees from Versant Health, outside the submitted work. The authors have
completed the ICMJE Declaration of Interest form (available upon request from the corresponding author), and declare
no further competing interests.

1 Li Q, Guan X, Wu P, Wang X, Zhou L, Tong Y, et al. Early transmission dynamics in Wuhan, China, of novel coronavirus-infected pneumonia. N Engl J Med. 2020;382:1199-207. Medline:31995857 doi:10.1056/NEJMoa2001316

2 Zhu N, Zhang D, Wang W, Li X, Yang B, Song J, et al. A novel coronavirus from patients with pneumonia in China, 2019. N Engl J Med. 2020;382:727-33. Medline:31978945 doi:10.1056/NEJMoa2001017

3 Huang C, Wang Y, Li X, Ren L, Zhao J, Hu Y, et al. Clinical features of patients infected with 2019 novel coronavirus in Wuhan, China. Lancet. 2020;395:497-506. Medline:31986264 doi:10.1016/S0140-6736(20)30183-5

4 Giovanetti M, Benvenuto D, Angeletti S, Ciccozzi M. The first two cases of 2019-nCoV in Italy: Where they come from? J Med Virol. 2020;92:518-21. Medline:32022275 doi:10.1002/jmv.25699

5 Phan LT, Nguyen TV, Luong QC, Nguyen TV, Nguyen HT, Le HQ, et al. Importation and human-to-human transmission of a novel coronavirus in Vietnam. N Engl J Med. 2020;382:872-4. Medline:31991079 doi:10.1056/NEJMc2001272

6 World Health Organization. WHO Statement on the second meeting of the International Health Regulations (2005) Emergency Committee regarding the outbreak of novel coronavirus (2019-nCoV) 2020. Available: https://www.who.int/news/item/30-012020-statement-on-the-second-meeting-of-the-international-health-regulations-(2005)-emergency-committee-regarding-theoutbreak-of-novel-coronavirus-(2019-ncov). Accessed: 20 January 2021.

7 World Health Organization. WHO Director-General's remarks at the media briefing on 2019-nCoV on 11 February 2020. Available: https://www.who.int/director-general/speeches/detail/who-director-general-s-remarks-at-the-media-briefing-on-2019ncov-on-11-february-2020. Accessed: 20 January 2021.

8 World Health Organization. WHO Director-General's opening remarks at the media briefing on COVID-19 - 11 March 2020. Available: https://www.who.int/director-general/speeches/detail/who-director-general-s-opening-remarks-at-the-media-briefing-on-covid-19_-11-march-2020. Accessed: 20 January 2021.

9 Cucinotta D, Vanelli M. WHO declares COVID-19 a pandemic. Acta Biomed. 2020;91:157-60. Medline:32191675

10 Chu DK, Akl EA, Duda S, Solo K, Yaacoub S, Schünemann HJ, et al. Physical distancing, face masks, and eye protection to prevent person-to-person transmission of SARS-CoV-2 and COVID-19: a systematic review and meta-analysis. Lancet. 2020;395:1973-87. Medline:32497510 doi:10.1016/S0140-6736(20)31142-9 
12 Bourouiba L. Turbulent gas clouds and respiratory pathogen emissions: potential implications for reducing transmission of COVID-19. JAMA. 2020;323:1837-8. Medline:32215590 doi:10.1001/jama.2020.4756

13 Kampf G, Todt D, Pfaender S, Steinmann E. Persistence of coronaviruses on inanimate surfaces and their inactivation with biocidal agents. J Hosp Infect. 2020;104:246-51. Medline:32035997 doi:10.1016/j.jhin.2020.01.022

14 van Doremalen N, Bushmaker T, Munster VJ. Stability of Middle East respiratory syndrome coronavirus (MERS-CoV) under different environmental conditions. Euro Surveill. 2013;18:20590. Medline:24084338 doi:10.2807/1560-7917. ES2013.18.38.20590

15 Chan KH, Peiris JS, Lam SY, Poon LL, Yuen KY, Seto WH. The effects of temperature and relative humidity on the viability of the SARS Coronavirus. Adv Virol. 2011;2011:734690. Medline:22312351 doi:10.1155/2011/734690

16 Coulliette AD, Perry KA, Edwards JR, Noble-Wang JA. Persistence of the 2009 pandemic influenza A (H1N1) virus on N95 respirators. Appl Environ Microbiol. 2013;79:2148-55. Medline:23335770 doi:10.1128/AEM.03850-12

17 Moriarty LF, Plucinski MM, Marston BJ, Kurbatova EV, Knust B, Murray EL, et al. Public health responses to COVID-19 outbreaks on cruise ships - worldwide, February-March 2020. MMWR Morb Mortal Wkly Rep. 2020;69:347-52. Medline:32214086 doi:10.15585/mmwr.mm6912e3

18 Aytogan H, Ayintap E, Özkalay Yilmaz N. Detection of Coronavirus Disease 2019 viral material on environmental surfaces of an ophthalmology examination room. JAMA Ophthalmol. 2020;138:990-3. Medline:32761201 doi:10.1001/jamaophthalmol.2020.3154

19 Dowell SF, Simmerman JM, Erdman DD, Wu JS, Chaovavanich A, Javadi M, et al. Severe acute respiratory syndrome coronavirus on hospital surfaces. Clin Infect Dis. 2004;39:652-7. Medline:15356778 doi:10.1086/422652

20 Rabenau HF, Kampf G, Cinatl J, Doerr HW. Efficacy of various disinfectants against SARS coronavirus. J Hosp Infect. 2005;61:10711. Medline:15923059 doi:10.1016/j.jhin.2004.12.023

21 Transportation Authority. How we're cleaning during the coronavirus pandemic. Available: https://new.mta.info/coronavirus/ cleaning. Accessed: 20 January 2021.

22 Centers for Disease Control and Prevention. Considerations for restaurants and bar operators. Available: https://www.cdc.gov/ coronavirus/2019-ncov/community/organizations/business-employers/bars-restaurants.html. Accessed: 15 June 2021.

23 New York State Department of Agriculture and Markets. Updated interim guidance for retail grocery stores during the COVID-19 public health emergency. Available: https://www.cdc.gov/coronavirus/2019-ncov/community/organizations/business-employers/bars-restaurants.html. Accessed: 20 January 2021.

24 Bike C. Caring for the Citi Bike community. Available: https://www.citibikenyc.com/blog/covid19. Accessed: 15 June 2021.

25 The COVID tracking project. Available: https://rt.live/us/NY. Accessed: 20 January 2021.

26 HealthData.gov. COVID-19 reported patient impact and hospital capacity by facility. Available: https://healthdata.gov/Hospital/COVID-19-Reported-Patient-Impact-and-Hospital-Capa/anag-cw7u. Accessed: 06 July 2021.

27 Ong SWX, Tan YK, Chia PY, Lee TH, Ng OT, Wong MSY, et al. Air, surface, environmental, and personal protective equipment contamination by Severe Acute Respiratory Syndrome Coronavirus 2 (SARS-CoV-2) from a symptomatic patient. JAMA. 2020;323:1610-2. Medline:32129805 doi:10.1001/jama.2020.3227

28 Ding Z, Qian H, Xu B, Huang Y, Miao T, Yen HL, et al. Toilets dominate environmental detection of severe acute respiratory syndrome coronavirus 2 in a hospital. Sci Total Environ. 2021;753:141710. Medline:32891988 doi:10.1016/j.scitotenv.2020.141710

29 Osman AA, Al Daajani MM, Alsahafi AJ. Re-positive coronavirus disease 2019 PCR test: could it be a reinfection? New Microbes New Infect. 2020;37:100748. Medline:32843984 doi:10.1016/j.nmni.2020.100748

30 Xing Y, Mo P, Xiao Y, Zhao O, Zhang Y, Wang F. Post-discharge surveillance and positive virus detection in two medical staff recovered from coronavirus disease 2019 (COVID-19), China, January to February 2020. Euro Surveill. 2020;25:2000191. Medline:32183934 doi:10.2807/1560-7917.ES.2020.25.10.2000191

31 Khokhar M, Roy D, Purohit P, Goyal M, Setia P. Viricidal treatments for prevention of coronavirus infection. Pathog Glob Health. 2020;114:349-59. Medline:32877308 doi:10.1080/20477724.2020.1807177

32 Asadi S, Cappa CD, Barreda S, Wexler AS, Bouvier NM, Ristenpart WD. Efficacy of masks and face coverings in controlling outward aerosol particle emission from expiratory activities. Sci Rep. 2020;10:15665. Medline:32973285 doi:10.1038/s41598020-72798-7

33 Nussbaumer-Streit B, Mayr V, Dobrescu AI, Chapman A, Persad E, Klerings I, et al. Quarantine alone or in combination with other public health measures to control COVID-19: a rapid review. Cochrane Database Syst Rev. 2020;4:CD013574. Medline:32267544

34 Passarelli VC, Faico-Filho K, Moreira LVL, Cunha AP, Carvalho JMA, Barbosa GR, et al. Asymptomatic COVID-19 in hospital visitors: The underestimated potential of viral shedding. Int J Infect Dis. 2021;102:412-4. Medline:33129961 doi:10.1016/j. ijid.2020.10.057

35 Centers for Disease Control and Prevention. Guidance for U.S. healthcare facilities about coronavirus (COVID-19). Available: https://www.cdc.gov/coronavirus/2019-ncov/hcp/us-healthcare-facilities.html. Accessed 20 January 2021

36 Rhee C, Baker M, Vaidya V, Tucker R, Resnick A, Morris CA, et al. Incidence of nosocomial COVID-19 in patients hospitalized at a large US academic medical center. JAMA Netw Open. 2020;3:e2020498. Medline:32902653 doi:10.1001/jamanetworkopen.2020.20498

37 Centers for Disease Control and Prevention. Research use only 2019-novel coronavirus (2019-nCoV) real-time RT-PCR primers and probes. Available: https://www.cdc.gov/coronavirus/2019-ncov/lab/rt-pcr-panel-primer-probes.html. Accessed: 20 January 2021. 